\section{An ever present adversary}

\author{
Stephen Hancocks OBE \\ Editor-in-Chief
}

Send your comments to the

Editor-in-chief,

British Dental Journal

64 Wimpole Street,

London,

W1G 8YS

Email bdj@bda.org
Glucose is described as a simple sugar, a monosaccharide. Sucrose, on the other hand, is a disaccharide composed of two simple sugars, glucose and fructose formed from carbon, hydrogen and oxygen atoms which combine to make it probably the single most abundant pure organic chemical in the world. Even if biochemically two 'simples' do not make a 'complex', in terms of history, culture, societal values, political consequences, economic effect and health outcomes, sucrose and other sugars are amongst the most significantly complicated substances that we could possibly have to deal with. Welcome to preventive dentistry.

With sugars and their effects it seems that everything starts as straightforward but then becomes progressively more difficult to explain. Take the well-worn message 'sugar plus bacteria equals acid, acid plus tooth equals caries'. We know that each of those four factors is subject to wide variability. For sugar it includes the type of sugar, the physical state (liquid, solid, sticky, hot, cold), the frequency with which it is consumed and the way in which it is consumed. In the case of bacteria it depends on the species, the micro-colonies within the biofilm, the extent to which plaque is disturbed or not during brushing and the relative penetration of the saliva. The acid effect will vary with plaque maturity and saliva composition. Host resistance or, tooth condition requires a library to itself; hard tissue resistance, fluoride content, enamel prism and dentine tubule formation all of which then lead on to treatment options ranging from varnish application to implants.

\section{GIVEN WITH LOVE}

Into this heady mix we also have to build the cultural elements. Sugar is woven into our lives with countless emotional overtones. We give chocolates and confectionery 'with love' for celebrations and congratulations, we 'treat' ourselves to 'naughty but nice' items to eat or drink. To suggest as oral health custodians that people deny this is to totally misunderstand motivation and the human condition.

So, where can we go in terms of helping to chip away at these bastions of ingrained sensitivities? Of relatively recent origin has come the realisation that oral health is not isolated from general health. Alliances with other health professionals may well provide a way forwards in terms of linking non-communicable conditions such as diabetes, heart disease and of increasing concern, obesity, with sugar consumption as well as other elements of diet. This, sensibly, should be undertaken in conjunction with the proven and potential associations between these and periodontal disease.

To this end, and also to start to tackle acid erosion from carbonated drinks, the BDA has joined forces with the Academy of Medical Royal Colleges (AMRC), which represents the majority of doctors in the UK in recognising that current strategies are failing to improve the diet and health of children and that an unprecedented coordinated approach is needed. ${ }^{1}$ In parallel, the Children's Food Campaign launched an initiative in March 2013 which highlights the need to change the way in which supermarkets and high street stores promote unhealthy food and drink to children. ${ }^{2}$

The BDA is therefore calling for six policy and legislative changes to help tackle the problems (www.bda.org/ makeamealofit):

- The introduction of a $20 \%$ tax on sugary carbonated drinks as proposed by the AMRC report; ${ }^{1}$ tax to also include diet versions which are equally damaging to teeth

- A ban on unhealthy food and drink advertising aimed at children

- The introduction of a maximum size of sweets and drinks sold in cinemas

- The removal of vending machines selling sweets and sugary/acidic drinks from schools and hospitals

- Restricting the availability of unhealthy food and drink at shop tills

- Extending the remit of the Advertising Standards Authority to cover product placement and checkout displays.

The likelihood of such changes being legally enacted is debateable but demands of this type can have other effects. For example, some years ago the 'Chuck Sweets off the Checkouts' campaign mediated by Action and Information on Sugar was effective in persuading, or perhaps shaming, supermarket chains to abandon the practice; although this has clearly made its insidious way back in the intervening time.

These initiatives, reflected in our recent paediatric dentistry themed issue as well as in the incoming BDA President Barry McGonigle's desire to improve caries prevention, are to be welcomed as reminders of the need for continued vigilance and action against preventable disease. Any victory, however small, would be sweet. But there, of course, is the conundrum.

1. Academy of Medical Royal Colleges. Measuring Up. The medical profession's prescription for the nation's obesity crisis. 2013. http://www.aomrc.org.uk 2. The Children's Food Campaign. Checkouts checked out. 2013. 